\title{
MAINTAINING "SYNK" IN DETROIT: Two Case Studies in the Remix Aesthetic
}

\author{
$\longmapsto$ Feature Article $\longrightarrow$ \\ Carleton S. Gholz \\ UNIVERSitY OF PITTSBURGH
}

\begin{abstract}
Advances in audio-visual remixing technologies have produced a significant, largely unintended, consequence: audiences at EDM performances are dancing less-if at all. Instead, utilizing digital mobile devices, audiences have increasingly become interactive media producers within an environment encouraged by savvy, former DJs. Drawing from the fields of EDM studies, sound studies and film studies, I outline the historical arc of the remix aesthetic by comparing and contrasting recent work by two long-time EDM artists from the Detroit-Windsor region, Jeff Mills and Richie Hawtin. These two artists were central to the global proliferation of EDM culture during its mass-communication phase. However, in an era of heightened media convergence what scholars have traditionally understood as EDM has irreparably changed. Mills and Hawtin have much to contribute to this apparent impasse.
\end{abstract}

KEYWORDS: EDM, film studies, film sound, remix aesthetic, soundscape, media convergence, Jeff Mills, Richie Hawtin, Plastikman

Carleton S. Gholz is a Cultural Studies Fellow and Doctoral Candidate in the Department of Communication at the University of Pittsburgh. In 2010 his first academic publication, "Welcome to tha D': Making and Remaking Hip Hop Culture in Post-Motown Detroit", was published in Represent Where I'm From: The Greenwood Guide to American Regional Hip Hop" (Greenwood Press, 2009). He will defend his dissertation, "Start Dancing! Communicative Spark and Sustainability in PostMotown Detroit”, this spring. See <http://csgholz.org>.

Dancecult: Journal of Electronic Dance Music Culture 2 (1): 45-62 ISSN 1947-5403 @2011 Dancecult http://dj.dancecult.net

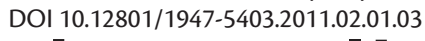

dsancecult 


\section{INTRODUCTION}

IN A 2004 PROMOTIONAL VIDEO FOR THE TOKYO CLUB WOMB, then resident Jeff Mills stirs up the crowd by manipulating a video of Chic performing their 1978 disco hit "Le Freak" on the famous dance TV show, "Soul Train", projected behind his elevated DJ booth. ${ }^{1}$ For the first half of the video the distinctive expression "freak out!" is delivered again and again-along with the band's distinctive chicken-scratch guitar-interlaced with a heavy electronic rhythm track by DK-8 entitled "Murder Was The Bass". ${ }^{2}$ Only three minutes long, the Womb clip is both tantalizing and complex. Multiple shots of the crowd, splitscreen shots of Mills and video images on the huge screen behind and above Mills' multiple pieces of equipment, not to mention the huge mirror ball, made the space difficult for the viewer-and we presume the club-goer-to navigate. Mills not only controls the sound but also the images. Jeff Mills is not a filmmaker and Womb is not a movie theater but a world famous super-club opened in 2000 to tap into the global DJ and club market revitalized in the 1990s rave era. For one night at least, Mills is both sound and lighting man. For the most part, from the 1960s until the late 1990s, in the club division of labor lighting and DJing have been separate roles, with the lighting technician reacting to the music coming from the club sound system. But now Mills - taking his cue from a growing tradition of artists working with new technologies to deliver video and sound-maintains both capabilities. ${ }^{3}$ With one hand he drops the bass of the techno track almost to silence, amplifies the Chic sample, with the projected video screening the group's singers repeat the same line and clap the same beat again and again as Mills weaves physically between different effects mixers, CD turntables and his own set of video monitors. Eventually he turns the techno track's volume up-the crowd screams as Mills lets them have it - a laser-like rhythm pounding through the club's world-class sound system. After pummeling his audience for about thirty seconds, he cuts the bass down again and focuses on cutting the audio-visual sample even faster. With just a repetitive motion of his finger, Mills transforms "freak out!" into "Ou! Ou-ou-ou-ou!" A split screen shows the screen light up with a strobe effect every time he hits the button. The crowd hollers more, lifting their arms in recognition, as Mills hits the button several times over, the strobes lighting up the crowd.

Discussions of the "remix aesthetic", theorized by scholars across multiple disciplines, have provided an opening to bring together the insights of film studies, sound studies and electronic dance music (EDM) studies, to build a more comprehensive and suggestive understanding of performances like Mills's Womb appearance, in which DJs utilize advances in digital technologies to exceed their sonic mandate. Jumping off a recent historical intervention within film sound studies and drawing from creative work by DetroitWindsor EDM artists Jeff Mills and Richie Hawtin, I will provide a description of the state of the remix aesthetic and address what is at stake for DJs and their audiences within this increasingly "convergent" culture (see Jenkins 2008). 


\section{"Remix ReduX"}

In her essay "Remix Redux: In the Silent Film Era, the Roots of the DJ”, Emily Thompson argues that for a brief moment in the late 1920s the film projectionist became a DJ. During Warner Bros' attempt to create sound pictures-films planned with their image and sound synced-after the emergence of the phonograph in the late 1920s, "Vitaphone" companies began to market technologies that allowed for film projectionists to cue film dialogue and music with the moving image. The technologies, generally wooden cabinets with two phonographs installed in them, look unmistakably like the two turntables that have been the club DJ standard for decades. ${ }^{4}$ Through archival research, Thompson uncovers that the makers of these machines were concerned that projectionists might jeopardize the machine's purpose to standardize the playback of image and sound throughout movie theatres. These companies had been entrusted with delivering a viewing experience for consumers without distractions and therefore dedicated to the production of story. Accordingly, machines were shipped with elaborate directions for projectionists. Among these was a warning not to rescue records that had fallen out of sync with the film but to start the next reel instead. However, Thompson discovered that some projectionists ignored their orders, using their hands to re-sync records and in some cases, especially for silent films not yet produced for phonographically supplied sound, improvise program music for movies. Given fire laws, Thompson argues that these projectionist-DJs might have even conducted themselves in front of the screen in the place normally reserved for the more variable, and from the point of view of the company more disruptive, film orchestra or pianist. The projectionist had become a performer. ${ }^{5}$

The moment did not last. Intensely fearful of the rupture caused by inconsistent playback, Vitaphone producers created elaborate accessories to ensure projectionists would not make mistakes, planned or otherwise. For instance, they included cardboard cutouts to be placed on records so that projectionists would know exactly where and when to sync the needle and record. Finally, with the coming of optical recording, the experimental period came to an end when technologies allowed film and sound to be synced to the same piece of celluloid, in effect cutting out the "middle man" (though Thompson remarks that these projectionists were just as likely women as men), increasing the standardization of playback. In her concluding thoughts, Thompson (2009: 28) remarks that:

Non-sync turntables could have allowed a new kind of sonic artistry to develop in 1929; they could have enabled a new musical creativity to be expressed through the personal selection and juxtaposition of recorded sounds. But within an industry and musical culture where standardization was the goal, the creative potential of this technology would not be fulfilled at this time. The musical possibilities of two turntables would remain latent for decades, awaiting a culture less captivated by top-down directives, an audience less enamored of master narratives.

Near the end of the essay, Thompson explicitly states that the audience she is imagining is that which emerged with hip hop culture in the 1970s, a cultural movement that, for 
Thompson, was able to take advantage of the possibility that "history itself is ultimately a remix, a reworking of old ideas into new contexts, a constantly changing juxtaposition of old and new" (2009: 28).

Thompson's concern with the history of the sound environment and its contemporary possibilities is not new. In her book The Soundscape of Modernity (2002), Thompson examined the emergence of modern acoustics to understand how public expectations of sound had shifted over the course of the 20th century. She argued that audiences began expecting spaces where sound would be heard authentically and consistently, without reverberation or distraction. However, Thompson argued that this modern set of expectations gave way in the 1970s to a desire for a variety of resonant spaces (2002: 324). If Thompson is correct and the modern soundscape was focused on providing an "aural anchor" (2002:321) in the midst of tremendous technological and societal change, then it follows that the postmodern soundscape is a potentially dizzying, sensuous place.

Thompson's nod to hip hop, DJing and the "remix aesthetic" within the history of soundcapes provides a suggestive atmosphere in which to think through the recent work of Jeff Mills. A DJ and electronic music producer, Mills' early career was inspired by the emerging mixing aesthetic of the 1970s pioneered by both disco and hip hop DJs. Entranced and apprenticed by an older generation of DJs and party promoters, his numerous residencies and DJ appearances at one-off events put him in the right place at the right time, as the execs of a struggling WDRQ - then a Top 40/urban station-heard salvation in Mills' live mixes. Within days of a live broadcast, Mills was asked to join WDRQ as "the Wizard", a name he'd called himself when one of the station's on-air personalities asked him for a DJ name. Immediately Mills was thrown on the air to compete with the popular Electrifyin' Mojo on WDRQ's urban opponent, WJLB. Though the two DJs respected one another and were on a first-name basis, their competitive spirit created a sonic backdrop for 1980s Detroit. From the beginning of his career, Mills was connected to a wide-ranging mass-communication network in the Detroit-Windsor region that included rental halls (or cabarets) and clubs, spaces that interacted with the sonic productions of radio and recording studios. However, the visual elements within the clubs, from the way strobes flashed to the visual style of dance fashion and movements were highly mediated by TV shows like "The Scene" on local, black-owned TV station WGPR. ${ }^{6}$ In a recent interview, Mills commented on this sonic and visual network which relied as much on his ears as his eyes:

Yeah of course [I watched "The Scene"]. Yeah who didn't? I think everyone did, looking to see what the people were listening to how they were getting on. I mean it was all connected, I mean we all knew each other. We were pushing music back and forth. They were listening to what I was doing [and] I was certainly watching what Nat [Morris, the host of "The Scene"] and all those guys were doing and we were pushing information back, back and forth, between them [the Electrifying] Mojo myself in certain clubs and record stores we were all very much communicating because we ... I guess we sensed-we knew it was a very special time and we were all maybe a little bit... I 
think most of the guys were a little bit older so they knew the difference between what it was and what had happened when Mojo and I began to really get aggressive with the music. Everybody was connected and everybody made money, everything progressed, all the clubs were packed, DJs were working, people were drinking [laughs]. It was a very interesting time and you know record sales, record stores were selling records, a lot of records at that time and people were listening to the radio and just on and on and on... ${ }^{7}$

However, according to Mills, that initial network shifted significantly in the late 1980s as hip hop culture outpaced Detroit's earlier electro-based tastes and "Detroit techno" began to become popular globally. Mills, both as a live, turntable-based DJ, and then as a producer of electronic music, emerged as one of the premier techno artists of global dance culture. Though not a mainstream star he is a legend amongst the thousands of fans that flocked to his club dates around the world, from Berlin to Japan. Regarded as a key innovator in the formation of "minimal techno" (Sherburne 2004: 321, 324), Mills continues to produce music and tour globally. ${ }^{8}$

In his fourth decade as an artist and performer, Mills began to engage silent film, first with Fritz Lang's Metropolis (in 2000) and then Buster Keaton's Three Ages (in 2004), creating new soundtracks for these silent films. ${ }^{9}$ However, for the latter film, Mills also released video remixes. At the time, these creative engagements for Three Ages were made possible by the Pioneer DVJ-X1 ${ }^{10}$ which allowed DJs to mix and scratch digital videos in the same way that they had been blending, mixing and, eventually, scratching vinyl records since the early 1970s. Unlike contemporary artists who create scores for silent film and pay close attention to the image in an attempt to maintain synchronicity (and, through analog instruments, authenticity), like the Alloy Orchestra, ${ }^{11}$ Mills' accompaniments in Three Ages vary from allegiance to the image in normal playback to playful audio-visual engagement when remixed. New digital technologies, specifically the DVD turntable mentioned above, have allowed Mills to present audiences with an un-nostalgic re-imagining of Buster Keaton based on the dominant interplay of sound over image. Mills is not the only, or even perhaps the most unique, example of a contemporary DJ remixing silent film. ${ }^{12}$ However, Mills' Three Ages remixes, and his accompanying commentaries, are fecund in terms of the remix scenario highlighted by Thompson. Where once there had been a film projectionist and a pit orchestra, with artists like Mills there emerges what one might call a "sound projectionist". Building upon Thompson's unique discovery in sound film history, it is this sound projectionist "revenge" scenario that I am interested in exploring.

Three Ages, released in 1923, features Buster Keaton in one of his early feature-length films. Keaton plays, according to an intertitle, the "faithful worshipper at Beauty's shrine", the young male lover who pursues actress Margaret Leahy through three historical periods, the "Stone Age", "Roman Times" and "Modern Times". Confounded by a stronger, richer and more conniving competitor, played by Wallace Berry, Keaton stumbles through each historical age until love-and Keaton's haphazard willfulness—wins out. Parodically based 
on D. W. Griffith's multi-period film, Intolerance: Love's Struggle Throughout the Ages (1916), Three Ages received supportive reviews from the Los Angeles Times at the time, in which it was praised for its fresh visual gags and its verisimilitude in the Roman sequences. ${ }^{13}$

In "Making the Remix", a short film accompanying his Three Ages release, Mills says that he uses the DVD turntable in order to create "a much more abstract, much more organic film". He then walks the audience through the editing process, demonstrating how he manipulates the image and accompanying sound using one hand on the circular tablet of the DVD player, his fingers on the myriad buttons along the edge of the machine, and then, later, both hands on an external visual controller, an Edirol V- $4^{14}$ made by Roland, which splits, distorts and replicates the image on a small video screen. While his hand is able to manipulate the forward progress of the film, the buttons allow him to create loops or samples of the image and music that he can then repeat at will. Motioning towards the repeating image of Leahy bringing food to her mouth at a restaurant with Keaton nearby, Mills states that "it's very easy to loop something like that, then with the turntable it's possible to affect it, so it's a very interactive feel that you have ... using this machine". Repeating the word "organic", he argues that the Edirol controller's strobe light effects and visual inversions allow the $\mathrm{VJ}$ to manipulate the presentation,

giving it a much more organic feel and also allowing the viewer to focus in on particular things that maybe would have been missed if watching the film at normal rate in the theater or watching it on TV. So it's possible then to ... to see this gesture that [the screen shows the product of Mills manipulating Keaton's eyes at the same restaurant table with Leahy] that happens so quickly, like his eyes, what he's looking at or exactly what she's touching on her face [back to full screen with Mills pointing and looking at video controller and screen]. It's these things that are often missed when watching at a regular speed. So, I can, very easy [sic] loop [back to screen] and focus on that gesture [shows the image looping and repeating a roll of Keaton's eyes] and you actually have time to actually see exactly what he's doing to get much more out of the dialogue and the script of it.

Why manipulate the image in this way? Why this focus on gesture as a way of getting more out of the dialogue when, except for a few rare intertitles in the whole film, there is no written dialogue? Why this aversion to "normal" playback conditions? Does he think that Keaton watchers have missed the humor and theatrical skill of Keaton rolling his eyes before? What strikes me most as I reflect on Mills' own interest in having his audience focus on gestures that are often missed in the viewing of the film is his lack of focus on story. Mills' remix of Three Ages seems uninterested in narrative. Instead he seems compelled by the interaction between sound and image for its own sake.

This interest seems to be confirmed in the interview about the remix itself. The track is seven minutes long, yet, after the quote mentioned above, Mills laughs, shrugs his shoulders and thanks us for listening to him talk. There are three minutes left. So the director of the documentary shows Mills at work in montage with the videos he is manipulating. 
What we see is Mills, concentrating on the movement of his own hands, his eyes flipping between the machines at his disposal and the images flickering on the screen. Despite the apparent ease of the technology, Mills' interactions with the turntable and mixer seem highly choreographed, the motions of a body deeply practiced in fast-paced hand-eye coordination. He taps the side of the turntable before hitting a button, and then hits it again. And again. He has found a rhythm he likes. Again. He bobs his head with the music, carefully winding and unwinding the circular platter at his fingertips. The remixes show the results: a magical series of visual gags on top of gags, Keaton's physical surprises and movements repeated, elongated, smeared, blurred and repeated again, all in service of Mills' musical accompaniment. It is as if Keaton, instead of landing on his behind after flopping down a fire pole because of his own ridiculous movements-due to his own comedic agency-is being pushed, pulled and tormented by repeated bass or bell-like synthesizer noises. Instead of being asked to comment or react to one fall, one preposterous movement of the head or arms, the audience is persuaded to stop thinking that it knows what the right reaction should be to the film's movements and instead take pleasure in the insistent tricks forcing the images to jump, slip back or stutter.

Mills seems to be a perfect candidate for film scholar Tom Gunning's "showman exhibitor" (1993: 10). Instead of offering narrative fulfillment, the DJ presents his audience with something lying dormant, according to Gunning, within the history of filmmaking:

Cinema as an attraction is that other purpose. By its reference to the curiosity-arousing devices of the fairground, the term denoted early cinema's fascination with novelty and its foregrounding of the act of display. Viewed from this perspective, early cinema did not simply seek to neutrally record previously existing acts or events. Rather, even the seemingly stylistically neutral film consisting of a single shot without camera tricks involved a cinematic gesture of presenting for view, of displaying. The objects of this display varied among current events (parades, funerals, sporting events); scenes of everyday life (street scenes, children playing, laborers at work); arranged scenes (slapstick gags, a highlight from a well-known play, a romantic tableau); vaudeville performances (juggling, acrobatics, dances); or even camera tricks (Melies-like magic transformations). But all such events were absorbed by a cinematic gesture of presentation, and it was this technological means of representation that constituted the initial fascination of cinema (1993: 4).

By watching Mills' remixes we can confirm his absorption in projecting and displaying images, as well as delighting in gags and, through dances and transformations, the carnivalesque. But, importantly, Mills is also projecting sound. The DJ is the (sound) projectionist returned from a cinematic space that, according to Emily Thompson, only existed in potential for a few years in the late 1920s. Like Buster Keaton himself in Sherlock $J r$. (1924), the projectionist (Mills) has fallen asleep only to walk into the screen and reimagine the performance from his vantage point. But, instead of stitching himself into an already closed narrative, Mills has stopped the story in its tracks. He freezes its characters' 
gestures until he lets them go-or not-understanding that it is the "here it is!" moment within the cinema of attractions that might inspire the dancers below.

Herein lies the ambivalence in Mills' own career. The sound projectionist can manipulate figures on a screen to suit his whim; he cannot do the same for dancers in a club. In his seminal work, Generation Ecstasy (1999: 225), Simon Reynolds took Mills to task for "conceptual overkill”. In the 1990s-from Reynolds' dance-friendly, populist, perspective-Mills spent far too much time imagining grand "Afro-futurist" visions than creating compelling, danceable music. Mills has not stopped thinking about space or the future. ${ }^{15}$

However, he has, from time to time, revived his identity as The Wizard. Why would Mills return to a DJ persona that arguably peaked in the late 1980s?

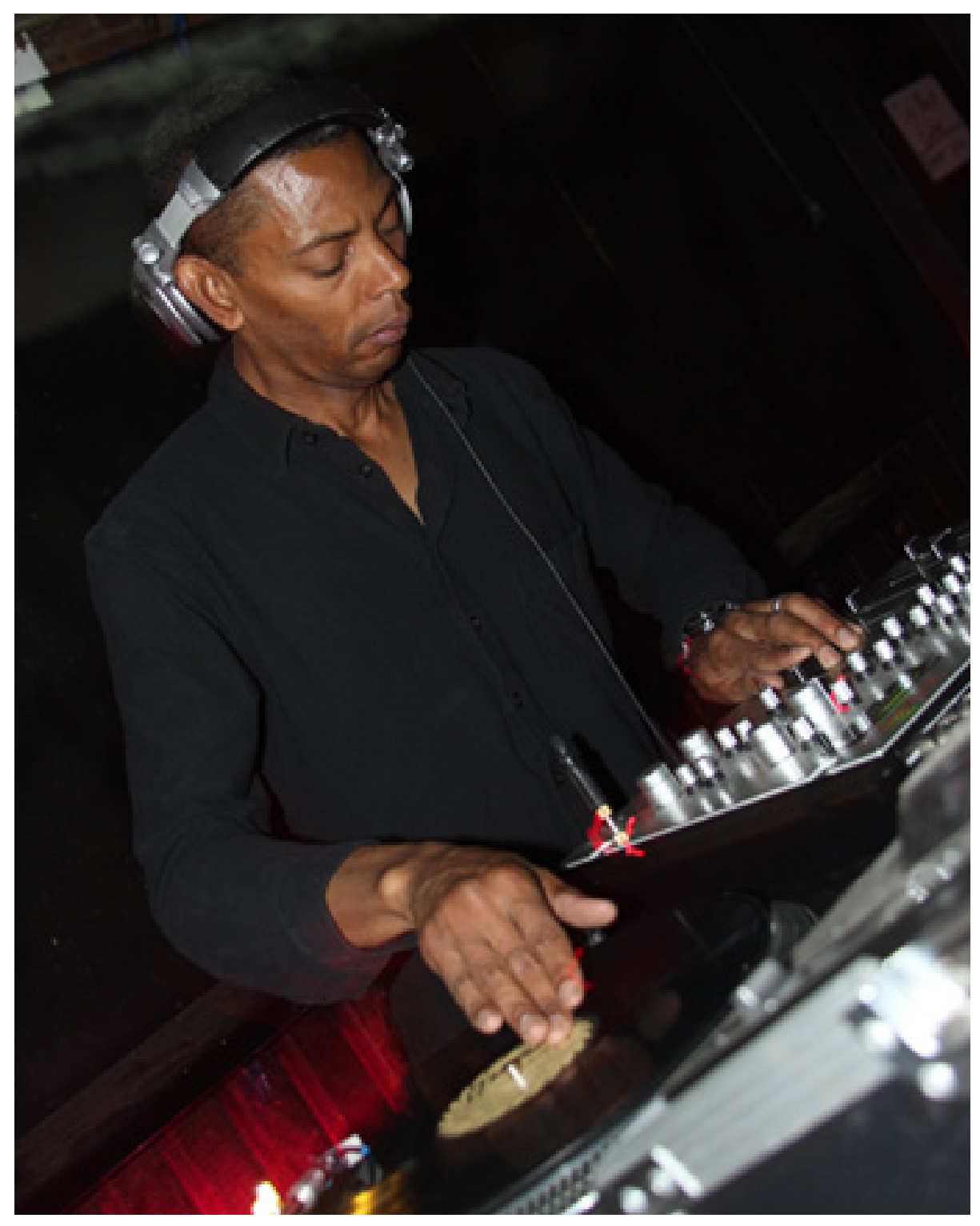

Figure 1. Jeff Mills in performance in Detroit, October 2010| Photo by Angie Linder. 
In an interview, conducted for the local Detroit alternative press paper Metro Times for an October 2010 performance by The Wizard, Mills acknowledged why he might be interested in performing a potentially older mix of records with turntables by showing concern for the state of dance music culture's musicians and audiences. When asked about the difference between the act of performing in a club versus executing a set for a radio show in the 1980s-in other words, whether actually seeing an audience mattered to his creative process as a DJ-Mills said:

It was little bit different back then because people used to dance more... so I could very easily imagine the type of dances from the "Schoolcraft" to all the kinds of things people were doing back then and try to imagine how they would be reacting to it. But now it's a little bit more different. The people are kind of dancing less or it's not really structured type of dancing so... so I use other factors to kind of decide how the music should be shaped, what the tempo should be, the texture, what things should be heard as the main component and things like that. But I am still a DJ . . . so in my mind I have a particular type of person wanting to hear a particular type of thing ... [I]t was easy to imagine how the people would react to those things because their dances were so influential it was really kind of directing the music in a certain way... It was easy to imagine when I was on the radio at night playing this stuff.

According to Mills, both nationally and globally audiences are no longer dancing or, perhaps more accurately, no longer dancing in the particular way they did in 1980s as Mills began to hone his craft. In those days, dancers improvised using a complex yet recognizable set of gestures and dance moves-some with well-known local names, like the "Schoolcraft", named after a Detroit West Side street—that Mills could and would recognize and react to during his sets and imagine later as he created music for radio and, eventually, his own recordings. He continues:

When people are dancing and you can clearly see that there is a certain type of art that's going behind what they're doing with their body to the music.... The DJ or the producer while watching it-you have to assume that the people are adjusting to it so well that they are beginning to relate to it [the music] physically and that you have to also assume that at some point they are going to feel so comfortable moving that they are going to modify what they are doing to modify their body to the music and that is what you're looking for if you're a DJ, if you are a producer, that's the stuff you're looking for, you're looking for the talkback from the music that you made or the music that you're playing and that gives you information of what to do next. ${ }^{16}$ When the people stop dancing you lose a large part of that communication. If they're just standing there and they're putting their hands in the air like they do now with hip-hop-and a lot of techno parties for one reason or another-the DJ can't see very clearly how the people are really reacting to it, if you can't see the legs move. It's that language that's been created for many, many, years that seems to be slowly dissolving away. Of course producers will begin to make music that will only get the hands up in 
the air and not necessarily make the people move because that's the information that he's getting. It's a two-way street and it's all connected. If I had to think whether the music was more interesting back then as opposed to now I would say "yes" and that's mainly because the people were dancing and there were structured dance moves that the people did to it which let you knew how the people were hearing it.

When DJs can't "read" their audiences-when the sounds they make do not conjure particular gestures of bodies in motion-then it is almost impossible, as Mills describes, to take them somewhere new. If this potentially tragic circumstance is juxtaposed with Mills' focus on gesture in the apparent comedic Three Ages remixes, the dark irony of this contemporary situation-its existential stakes-become more apparent. In the remixes, Mills is helping to create "spontaneous" gestures that are slowly disappearing in the clubs that he plays in. Why are these gestures disappearing? One problem, Mills argues, is when audiences consist primarily of young fans. Mills contends that multigenerational, racially and sexually diverse, audiences tend to educate their dancers and even DJs into the rituals of the dance. However, this mentoring process has become rare in Mills' estimation. Another reason Mills cites for the lack of dancing is that digital DJ technology has removed the risk of making mistakes - and the potential to build up mixing skills to make mistakes creatively. DJs, no longer forced to touch records to keep them synced, have lost part of their own creative practice. ${ }^{17}$

Thompson's remix aesthetic appears theoretically responsive enough to jump from 1920s movie houses, to 1970s hip hop DJs, to silent film remixes as Mills has created them. However, the overall conundrum of the remix aesthetic for the DJ that Mills has outlined remains. The "sound projectionist" VJ may be able to capture and manipulate images-especially human figures in motion-in a pedagogic gesture meant, as it seems to be in Mills' case, to remind audiences of the possibilities of EDM. When Mills performs for seated audiences, as he sometimes does when performing new soundtracks, this highly didactic audio-visual opportunity made possible by advances in digital technologies seems wholly appropriate. However, the sound projectionist is not a DJ in the EDM sense of that term. The demise of DJing as an analog process utilizing turntables and vinyl records is inextricably linked to the cessation of dancing as Mills has understood it through his career. DJ mixing with Technics 1200 s, vinyl records and a mixer - as consciously taught and circulated by a core group of DJs across the US and Jamaica, eventually finding a global mass audience of dancers-has proven to be a minority movement, a minor practice that, though influential, according to one of its most profound practitioners, has failed to maintain the appeal of its central, vibrating, creative dynamic: the discourse of the dance.

\section{HAWTIN: Restoring "SYNK"}

On Friday night before the 2010 Movement Festival-the tenth anniversary of Detroit's electronic dance music festival in Hart Plaza-festival co-creator and "Creative Director", Carl Craig, hosted an evening of films about, and inspired by, Detroit musicians. 
The event, "2010: A Detroit Odyssey", featured the first showing of the festival documentary The Drive Home, a French-made film Cycles of the Mental Machine that followed the voice and ideas of former radio DJ the Electrifying Mojo, and a video recording of a symphonic concert dedicated to the late Detroit-born hip hop producer J Dilla (born James Yancey) called Timeless Suite for Ma Dukes. These apparently realistic representations of Detroit music and culture were shown amidst the 1920s science fiction film Metropolis, originally directed by Fritz Lang, and, as we have seen, "remixed" by Jeff Mills.

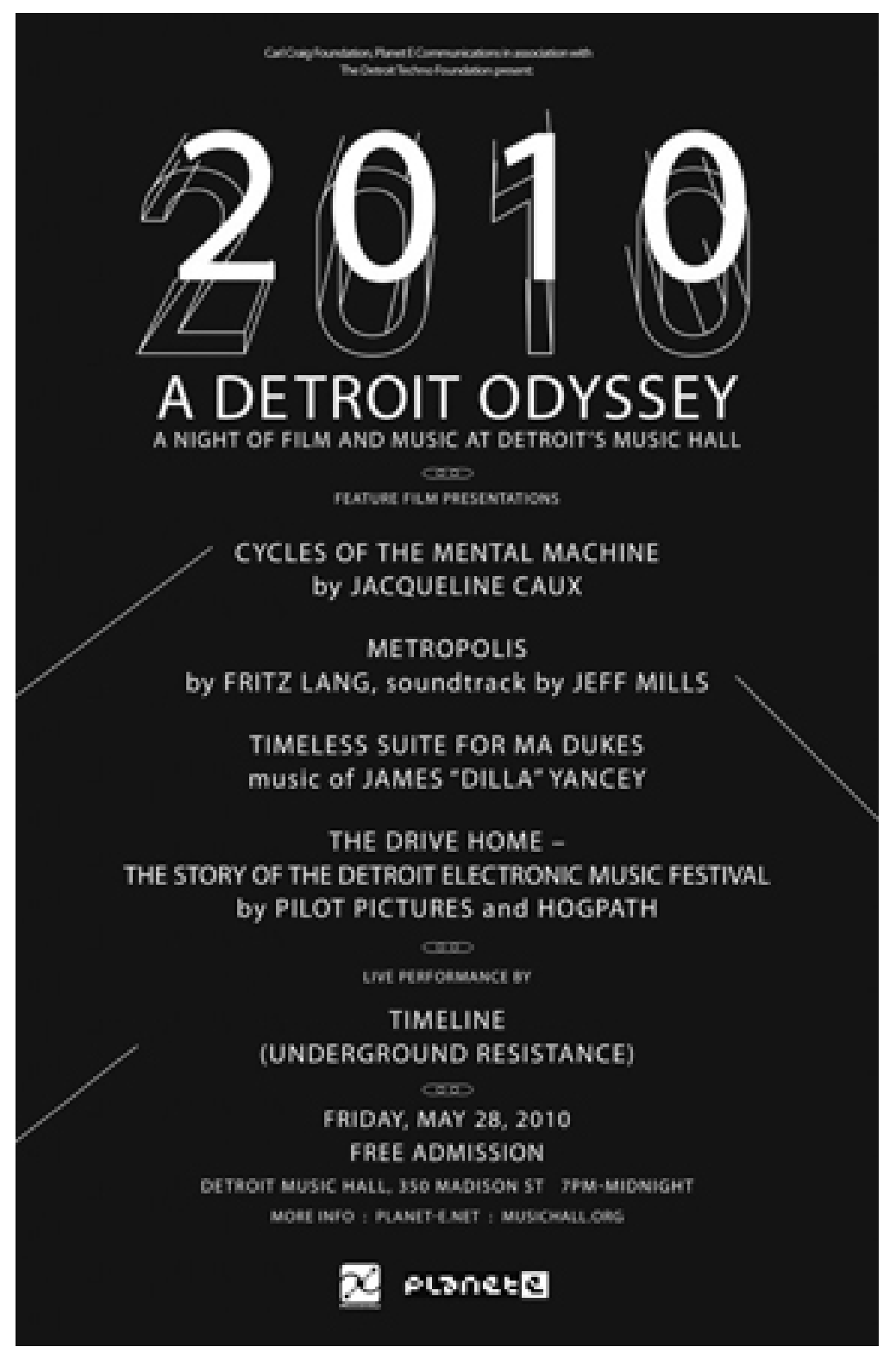

Figure 2. Flyer for "2010: A Detroit Odyssey”. 
Despite the free admission and the rare lineup of filmic texts, the Music Hall event was sparsely attended. However, anyone who stayed for the festival would have recognized that this night of films was not the only "screen"-based moment of the weekend. On the festival's opening night, Richard Hawtin, performing as long-time moniker and live performance alter-ego Plastikman, brought a cutting-edge, hour-long performance to Hart Plaza's main stage that featured him performing surrounded by a screen consisting of light-emitting diodes (LEDs), an updated version of "The Cube" developed for the 2008 "Contakt" tour by visual artist Ali Demeril for Hawtin and other artists from the Windsorite's M_nus record label. This spectacular sonic performance was fully intertwined with its carefully crafted visual elements conducted on the screen. In fact, it was clear from the beginning of the performance, when a voice began speaking and a line of light began fluctuating along with it, as in a spectrogram, that considerable care had been taken to make sure sound and light were in sync. ${ }^{18}$

The hour-long performance featured all the startling loud bass pulses and crisp, crackling drum patterns, as well as the obligatory ups-and-downs, and the now-you-hear-it, nowyou-don't deliveries, that seem to be crucial to the execution of contemporary EDM performance. However, it was the visual cues that helped to explicitly center the audience's attention. Except for a handful of key moments where Hawtin's shadow was shown to the audience to be within the curtain of LEDs, the artist himself was not the apparent center of the performance. Instead eyes were on the screen. First, it was the sine wave reacting as both mouth and spectrogram to a deep voice familiar to Plastikman fans, a voice that I imagine is the superego of the artist himself-or perhaps better, the audience's collective superegotelling us what not to think or do. The voice has featured in many Hawtin performances over the years, and in his Plastikman full-length album, Closer (2003). The spoken word lyrics captured the migraine-slowness of a bad acid trip, telling the audience not to ask him but to "ask yourself". Plastikman, through sound and image, seemed to channel The Wizard of $\mathrm{Oz}$, annoyed at our presence yet at least sympathetic enough to deliver the sulfur and fake thunder that the audience demands / wants / expects.

The images generated by the thousands of LED dots on the screen flickered fiercely at times, simulating eclectic spinning patterns, while at others stayed static. Shapes, repeating, shifting, blinked with the music. Some of the visuals changed with the beginning of a new track and therefore seem pre-programmed, more like music videos then visual patterns created by the sounds. Instead of an iTunes visualizer reacting to a set list, the effect seemed more didactic, meant to be a direct visual commentary on, for instance, the computer code script we are so familiar with from the Matrix films. In red and orange, black and white, and "computer" green, the images moved with the sound, manipulated by the triggers inside Hawtin's cocoon-like enclosure via wireless networks and hundreds of carefully hidden cords. It is unclear what the best seat in the house is at a performance like this when the screen is circular and speakers are seemingly positioned everywhere within a cement bowl-though the sight-lines of audience members behind the stage were restricted by the scaffolding that surrounded Hawtin's circular command center. At times the emitting visuals made the circular "Cube" appear like it was levitating just above the stage. 


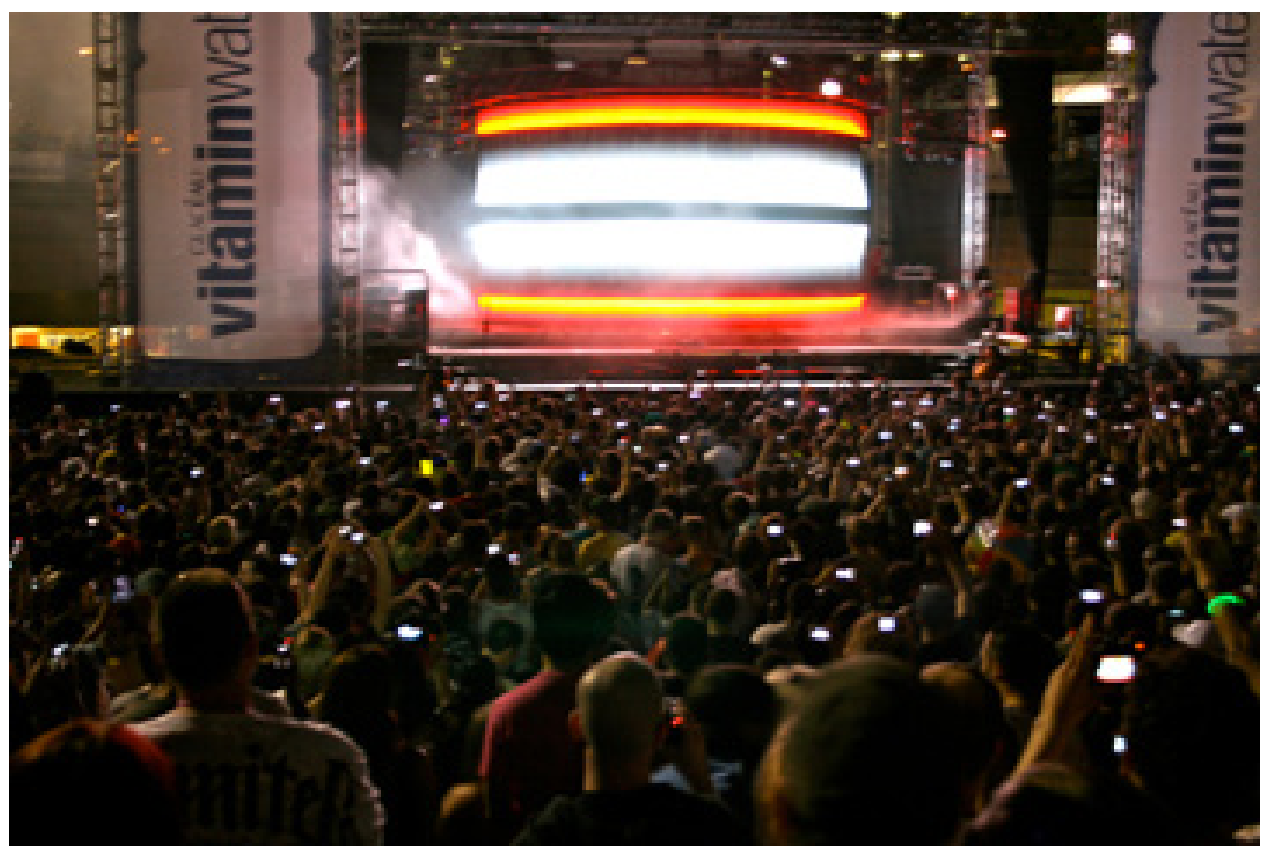

Figure 3. Plastikman live, opening night of the 2010 Movement Festival in Detroit. Photo: Carleton Gholz.

The "screen" did not end with the scrim of on-stage LED projectors. Instead, the audience members themselves, many with iPhones, turned their own screens towards the stage-and not merely to take pictures or video of the spectacle. Instead, through an iPhone application called "Synk", the "users" were able to "participate in an experiment in audience-performer interaction aiming to blur the lines of perception and participation". The description continues on the Plastikman website:

They [the audience] will connect to the PLASTIKMAN Wi-Fi network available at each show, and after being notified by a vibration triggered by certain moments in the performance, be able to contribute and interact by reorganizing word samples, viewing the venue from the Plastikman perspective, and seeing the real-time programming of the drum and percussive elements and effects. In between the performances, the application is in sleeper mode and functions as a Plastikman atmospheric location shifter. Using the iPhone's built in microphone and accelerometer, users will be immersed in a Plastikman environment. For best results, use headphones. ${ }^{19}$

I did not have an iPhone during the performance so cannot comment from experience on the "Logikal", "Kamera", "Synkotik" and "Konsole" options within the iPhone "Synk" application itself. However, drawing from the video clips offered in the "Watch" section of the Plastikman Live Web site, I can point out two things that seem important for performance and the remix aesthetic that I have been discussing. First, Hawtin as Plastikman 
has moved far beyond turntable-like controllers in order to manipulate sound and image and embraced touch-pad technologies like Griid (via http://liine.net/griid/en/index.html) to navigate both the macro (the overall shape and contour of sounds) and micro moments (specific notes, passages, rhythms) of the performance. I can already sense, in my attempt at describing this shift, the utilization of metaphors from architecture and sculpture-"shape and contour" - and therefore a potential break from the circular, repetitive, (re)mix metaphors offered by Thompson. Second, the number of people (and the finances) required for such a performance continues to grow, even from the complete "club" experience that Hawtin has classically offered whenever he comes "home" to Detroit (Hawtin now lives full-time in Berlin), hearkening back to his earlier career DJing at elaborately staged parties in spaces as varied as warehouses to country fields. In this way, the club or rave experience seems to have dissolved into a larger concert experience, comparable to witnessing Pink Floyd's "The Wall". ${ }^{20}$

However, it is from the audience perspective where Hawtin's rupture within the remix aesthetic can be understood acutely. From the Millsian perspective offered earlier, the audience is not dancing in any recognizable way-I saw no one doing the "Schoolcraft"and, even if they had been, Hawtin as Plastikman could not have seen them within the stage-sized screen that enveloped him. Arguably, Hawtin had the audience's attention but the feedback between instrument and musician, sound and body, DJ and audience / dancer, was not the only, or primary, means of syncing with them. Whether it is by Tweeting the tracks he plays when he DJs to non-dancing audiences thousands of miles away (via http:// twitter.com/rhawtin_live) or, at Movement, by providing a way for audiences to "Synk" with his performance both inside and outside of the club, Hawtin is holding himself open to what is new and possible in the convergence of various technologies of performance. In the process, he has kept himself at, or at least near, the cutting edge of what it means to "interact" with a crowd in the diffused, digital way that social networking and wireless technologies have made possible. The revenge of the sound projectionist is complete-we have only to throw our hands in the air to celebrate.

\section{CONCLUSION}

In 2001, John Acquaviva and Richie Hawtin, cofounders of the Plus 8 Record label and longtime creative collaborators, introduced Final Scratch, a combination softwarehardware package then capable of allowing DJs to manipulate digital music files on their laptops via analog turntables. ${ }^{21}$ The technology made it possible for a DJ to leave their record collection at home when they toured but did not, according to Acquaviva, eliminate the joy of touch. Speaking to MTV Germany at the time, Acquaviva said: "I told you, you have to touch it. Once you touch it, it's like falling in love". ${ }^{22}$ However, in 2008, after the purchase of Final Scratch by Native Instruments and the increasing efficiencies of software and hardware, Hawtin, Acquaviva's partner, disconnected his turntables completely. ${ }^{23}$ The result is a situation in which the computer has completely taken over what was once regarded as the key DJ talent—-the hand-ear-eye gesture required to forge the mix. 
Now-eyes committed to the computer screen, ears tuned to the invariant loop, and hands ready to push, turn, twist and clap-the so-called DJ reorganizes his senses to intensify "the desire for the beat" (Butler 2006: 92). Hawtin's response in 2008 was not melancholic though: "Allowing the computer to do one thing is only boring", Hawtin said in a YouTube clip showcasing his setup at the time, "if you don't use the time the computer saves you to do something else". For Hawtin, that something else is the ability to focus on loops and effects. Hawtin continues to experiment with this "something else". ${ }^{4}$

For now, Richie Hawtin will continue to be a "DJ", albeit a digital one, if only because of the expense and systematized planning required for Plastikman performances. Drawing from the fields of film studies and club culture studies, I have argued that a transitional moment has been reached where a set of musical practices and expectations with respect to dance music has been displaced-perhaps permanently-by a sonic environment that more persistently engages the possibilities of digital music-making and social networking. The result, for DJs like Mills, is the impending death of an art form that worked, more or less continuously, since the 1960s. For others, interpreting Hawtin's performance and web presence, the shift is merely another example of change within an entertainment environment that emerged from technological innovation and complex, sometimes ambiguous, audience feedback. Mills, via VJing and film remixes, as well as online via his Facebook page, has shown that he can engage his audience similarly to Hawtin; though there is none as yet, I will not be surprised if Axis Records, Mills' label, rolls out an iPhone application. However, Mills clearly regrets the disappearance of dancers who, through their own agency, collaborated with him in the mix. In Hawtin's performance as Plastikman it seemed that technological progress might override such losses. Nonetheless, the crowd seemed to be enraptured.

At the end of the Plastikman Movement performance, however, Hawtin, the man not the scientist, came out from behind the screen for an encore, perhaps hinting nostalgically to an earlier remix moment. An analog drum machine on a stand was produced from below the stage and Hawtin began to "perform" his most famous early 1990s track, "Spastik". The gesture was anti-climatic and highly personal. As Dan Sicko discussed in Techno Rebels, Hawtin had been shocked at how certain European audiences had synced with the aggressiveness of his productions of the early 1990s, at times shouting anti-Semitic chants during DJ performances (2010: 89-90). Detroit producers, according to Hawtin, were "not making hard music just for the sake of it... We weren't slamming people over the head just for the sake of it" (quoted in Sicko 90). The gesture of coming out from the screen brings this perspective home. Hawtin, after pummeling his audience sonically and visually, still wants to sense their reaction directly-he does want what Mills calls "feedback." If this is true, then perhaps dance critics like Beverly May (2000) are correct, that indeed the ideal of EDM, as practiced by Hawtin, is not to sideline sonic-thinking through distraction but instead to produce the possibility for "unified concentration" and "collective focus". However, Mills' observations are still cogent. A particular form of creative, imaginative, dance called forth by a DJ immersed in the remix aesthetic has ended. This does not 
necessarily mean that dancing has ended or that music no longer propels humans to create new gestures or arm them with, as Kenneth Burke (1973: 304) might have said if he had ever attended a disco, "equipment for living". However, it does mean that a particular mode of aural/visual production - the province of the DJ-has become unhinged from its audience. What has emerged are performances where the sound projectionist is confronted not with a seated audience of film-goers, as in the 1920s, but with a sea of savvy digital producers, hands filled with interactive, audio-visual devices, their attention not focused on their feet but themselves.

\section{NOTES}

1 "Jeff Mills: Time Sensitive 2004": <http://www.youtube.com/watch?v=v8wvLTuBYdw> (accessed 12 February 2011).

2 I am indebted to comments on the aforementioned YouTube video identifying this track. A version of the track is available on YouTube: <http://www.youtube.com/watch?v=96AgOqQO1Q4 $>$ (accessed 6 February 2011).

3 Jeff Mills is not the first artist to appropriate or remix video and sound together. For a brief overview of the "remix era" that includes a discussion of trends in audio and visual remixing throughout the 20th century, see Lev Manovich, "What Comes After Remix?" (Winter 2007). Available on "Lev Manovich: ARTICLES" < http://manovich.net/articles/> (accessed 31 January 2011).

4 An image of this "coffin" can be seen in the online edition of Thompson's article, available via Cabnet: <http://www.cabinetmagazine.org/issues/35/thompson.php > (accessed 6 February 2011).

5 For a history of this era from the point of view of pit orchestras and musician, see Kelley (2001).

6 A brief history of "The Scene" was reported on local Detroit TV station UPN50 in 2006. See "Detroit Jit (The Scene)" < http://www.youtube.com/watch?v=0fdzDKp4EO4 > (accessed 6 October 2010).

7 Jeff Mills, interview with the author (online via Skype), 20 September 2010.

8 For an updated overview of Mills' current work see the Axis Records website $<$ http://www. axisrecords.com $>$ and Mills' Facebook page < http://www.facebook.com/JeffMills $>$.

9 Mills' version of Metropolis is not yet available on DVD, though it has been released on CD. A promo video for his soundtrack is available on YouTube: <http://video.google.com/videoplay?

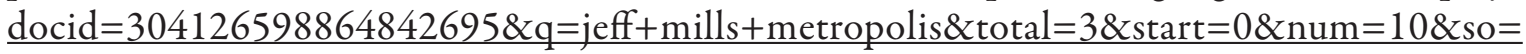
0\&type $=$ search\&plindex $=0>($ accessed 19 February 2010). Based on my memory of watching Metropolis with Mills' soundtrack in Detroit during the 2010 Movement Festival, it would seem that it was Mills' intention to sync his music with the film. According to a reviewer of this article, the "live" performance by Mills of Metropolis at the 2004 Sonar Festival in Barcelona was also faithful to the film. Though I do not discuss it here, in 2009 Mills performed a new soundtrack for Cecil B. DeMille's The Cheat and this year has produced a soundtrack for Sergei Eisenstein's October (see Picard 2011).

10 "DVJ-X1-Pioneer Product Archive", <http://www.pioneer.co.uk/uk/products/archive/ DVJ-X1/index.html $>$ (accessed 19 February 2010). 


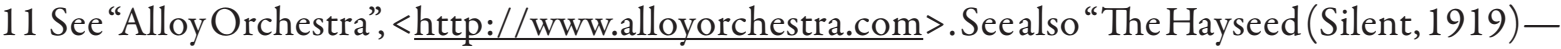
Fatty Arbuckle, Buster Keaton 1/3": <http://www.youtube.com/watch?v=WO2URF7eLUM > for an example of their work (accessed 19 February 2010).

12 See, for instance, Paul D. Miller a.k.a. DJ Spooky that Subliminal Kid, "Notes for Paul D. Miller's 'Rebirth of a Nation'-remix of D.W. Griffith's 1915 film 'Birth of a Nation"” < http:// www.djspooky.com/articles/rebirth.php> (accessed December 2007).

13 "Buster in Costume Stuff”, Los Angeles Times, 18 July 1923: WF10 and "Recalls Days of Old Rome in Photoplay", Los Angeles Times, 2 March 1923: II 11.

14 "The V-4 is a 4-channel Video Mixer made for portable or fixed installation use. It is ideal for use in nightclubs, places of worship, theatres, and other live performances. The compact design of the V-4 gives you the freedom to make your video sources come alive". Quoted in "Roland Systems Group U.S.-Product: V-4”, <http://www.rolandsystemsgroup.com/products/100004 > (accessed 12 February 2011).

15 For instance, on 19 June 2010, Mills returned to Detroit for a performance called "Something in the Sky" in which he played new tracks via two CD-DJ turntables while images of supposed UFOs and UFO sightings played on a screen. See < http://www.residentadvisor.net/event. aspx?164048> (accessed 31 January 2011).

16 This description of EDM dance by Mills is consonant with work by ethnomusicologists (see Butler 2006: 72-5).

17 Mills has attempted to address this situation through vinyl-only releases like "The Drummer" on his Purposemaker imprint in 2009 which he explained are designed to be manipulated by DJs-not played straight through without engagement. See < http://www.axisrecords.com/ $>$.

18 For a technical description of Hawtin's performance, see Amanda Connon-Unda, "Plastikman Live transforms Detroit" < http://www.musingsonspace.com/2010/08/04/plastikman-livetransforms-detroit/> (accessed 4 August 2010).

19 All quotes from the "Synk iPhone Application" portion of the "Plastikman" website < $\underline{\text { http:// }}$ plastikman.com> as accessed on 15 October 2010.

20 Roger Waters, quoted from "Roger Waters: The Wall Live: Official Site": "I recently came across this quote of mine from 22 years ago: 'What it comes down to for me is this: Will the technologies of communication in our culture, serve to enlighten us and help us to understand one another better, or will they deceive us and keep us apart?' I believe this is still a supremely relevant question". Quote from 11 April 2010 on < http://www.roger-waters.com $>$ (accessed 20 October 2010).

21 See "10 Years of Digital DJing With Richie Hawtin" from Urb < $\underline{\text { http://www.urb. }}$ com/2011/01/25/10-years-of-digital-djing-with-richie-hawtin/> (accessed 31 January 2011).

22 "John Acquaviva demonstrates FinalScratch @ MTV Germany" via < http://www.youtube. com/watch? $=$ zFyOJGVlbdo $>$ (accessed 31 January 2011).

23 "Richie Hawtin on his Traktor Scratch DJ setup-Pt 1" via < http://www.youtube.com/ watch?v=J1H9W iLffo > (accessed 31 January 2011).

24 "Ean Goldne interview's [sic] Richie Hawtin at Namm 2011 (Future of Digital Djing)" via $<$ http://www.youtube.com/watch? $\mathrm{v}=\mathrm{vOksLpUj1 \textrm {kk }}>$ (accessed 31 January 2011). 


\section{REFERENCES}

Burke, Kenneth. 1973. The Philosophy of Literary Form. Los Angeles: University of California Press.

Butler, Mark. 2006. Unlocking the Groove: Rhythm, Meter, and Musical Design in Electronic Dance Music. Bloomington: Indiana University Press.

Connon-Unda, Amanda. 2010. "Plastikman Live Transforms Detroit". Musings on Space. 4 August: <http://www.musingsonspace.com/2010/08/04/plastikman-live-transforms-detroit/> (accessed 16 January 2011).

Gunning, Tom. 1993. “Now You See It, Now You Don't': The Temporality of the Cinema of Attractions". Velvet Light Trap, no. 32 (Fall): 3-12.

Jenkins, Henry. 2008. Convergence Culture: Where Old and New Media Collide. New York: New York University Press.

Kelley, Robin D. G. 2001. "Without a Song: New York Musicians Strike out against Technology”. In Three Strikes: Miners, Musicians, Salesgirls, and the Fighting Spirit of Labor's Last Century, ed. Howard Zinn, Dana Frank, and Robin D.G. Kelley, 119-55. Boston: Beacon Press.

May, Beverly. 2000. "Participatory Theatre: The Experiential Construct of House and Techno Music Events". Canadian Theatre Review, no. 103 (Summer): 9-13.

Pavlik, John V., and Shawn McIntosh. 2011. Converging Media: A New Introduction to Mass Communication. 2nd ed. New York: Oxford University Press.

Picard, Grégory. 2011. “Techno Experimentalist Jeff Mills Puts a New Spin on an Eisenstein Film," ARTINFO France (4 January). <http://www.artinfo.com/news/story/36680/techno$\begin{array}{lll}\text { experimentalist-jeff-mills-puts-a-new-musical-spin-on-an-eisenstein-film/> } & \text { (accessed } 7\end{array}$ February 2011).

Reynolds, Simon. 1998. Generation Ecstasy: Into the World of Techno and Rave Culture. Boston: Little, Brown and Company.

Sherburne, Philip. 2004. "Digital Discipline: Minimalism in House and Techno". In Audio Culture: Readings in Modern Music, ed. Christoph Cox and Daniel Warner, 319-26. New York: Continuum.

Sicko, Dan. 2010. Techno Rebels: The Renegades of Electronic Funk. 2nd ed. Detroit: Wayne State University Press.

Thompson, Emily. 2002. The Soundscape of Modernity: Architectural Acoustics and the Culture of Listening in America, 1900-1933. Cambridge: MIT Press.

_- - 2009. "Remix Redux: In the Silent Film Era, the Roots of the DJ". Cabinet, no. 35 (Fall): $23-28$. 